
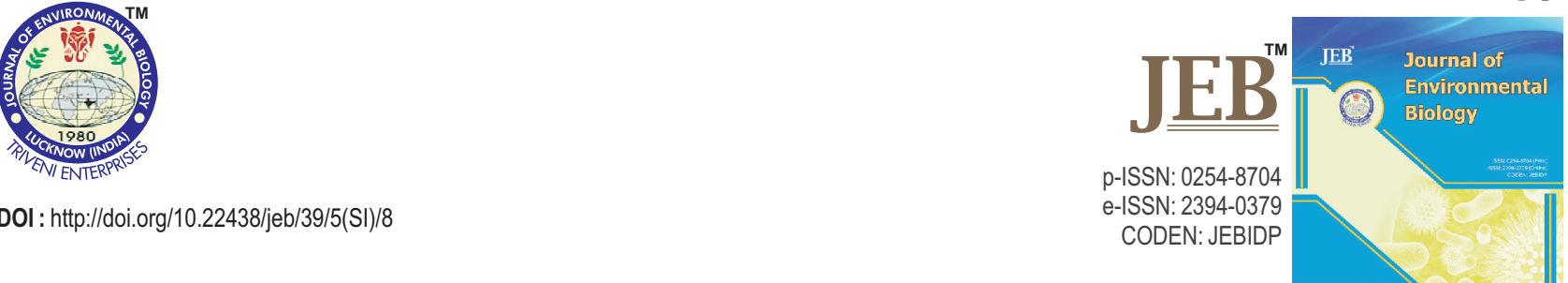

\title{
Effects of dietary steviol glycosides on the growth, feed intake and intestinal short-chain fatty acids in red hybrid tilapia
}

\section{Authors Info}

J.M.S. Choy', N. Romano ${ }^{2,3 *}$, M. Ebrahimi ${ }^{4}$ and Mohd. S. Kamarudin ${ }^{2}$

${ }^{1}$ Ministry of Higher Education Malaysia, Jerantut Community College, 27000 Pahang, Malaysia ${ }^{2}$ Department of Aquaculture, Faculty of Agriculture, Universiti Putra Malaysia, 43400 Serdang, Selangor, Malaysia

${ }^{3}$ Aquaculture/Fisheries Center, University of Arkansas at Pine Bluff, 1200 North University Drive, Pine Bluff 71601, AR, USA

${ }^{4}$ Department of Veterinary Preclinical Sciences, Faculty of Veterinary Medicine, Universiti Putra Malaysia, 43400 UPM Serdang, Selangor, Malaysia

*Corresponding Author Email : romano.nicholas5@gmail.com

Key words

Feed attractant Red hybrid tilapia Short chain fatty acids Stevia rebaudiana Steviol glycosides

Publication Info

Paper received : 08.08.2017 Revised received: 09.10.2017 Re-revised received : 15.11.2017 Accepted : 28.12.2017

\section{Abstract}

Aim : Stevia is a natural sweetener but is not readily metabolized or fermentable in animals. It may have potential as a feed attractant; however, there is limited information on the effects of dietary Stevia in fish.

Methodology : A 76-day-study was performed to assess the growth, feed intake, body indices, muscle proximate composition and intestinal short chain fatty acids (SCFA) in red hybrid tilapia fed with increasing Stevia (steviol glycosides) at 0,1,3 and 6\%. A second experiment was performed to determine any changes in plasma glucose, cholesterol or triglyceride levels in red hybrid tilapia at 1, 3, 6, 12 and $24 \mathrm{hr}$ after being fed 0 or $6 \%$ Stevia.

Results: In experiment 1, dietary Stevia had no significant effect $(p>0.05)$ on any of the measured parameters in tilapia and in experiment 2, dietary Stevia had no significant effect $(p>0.05)$ on the tested plasma biochemistry.

Interpretation: These findings indicate that Stevia did not improve diet palatability to tilapia, as well as not being metabolized for energy or fermented. Based on these findings, there is no advantage to including Stevia at the tested levels in the diets of tilapia.

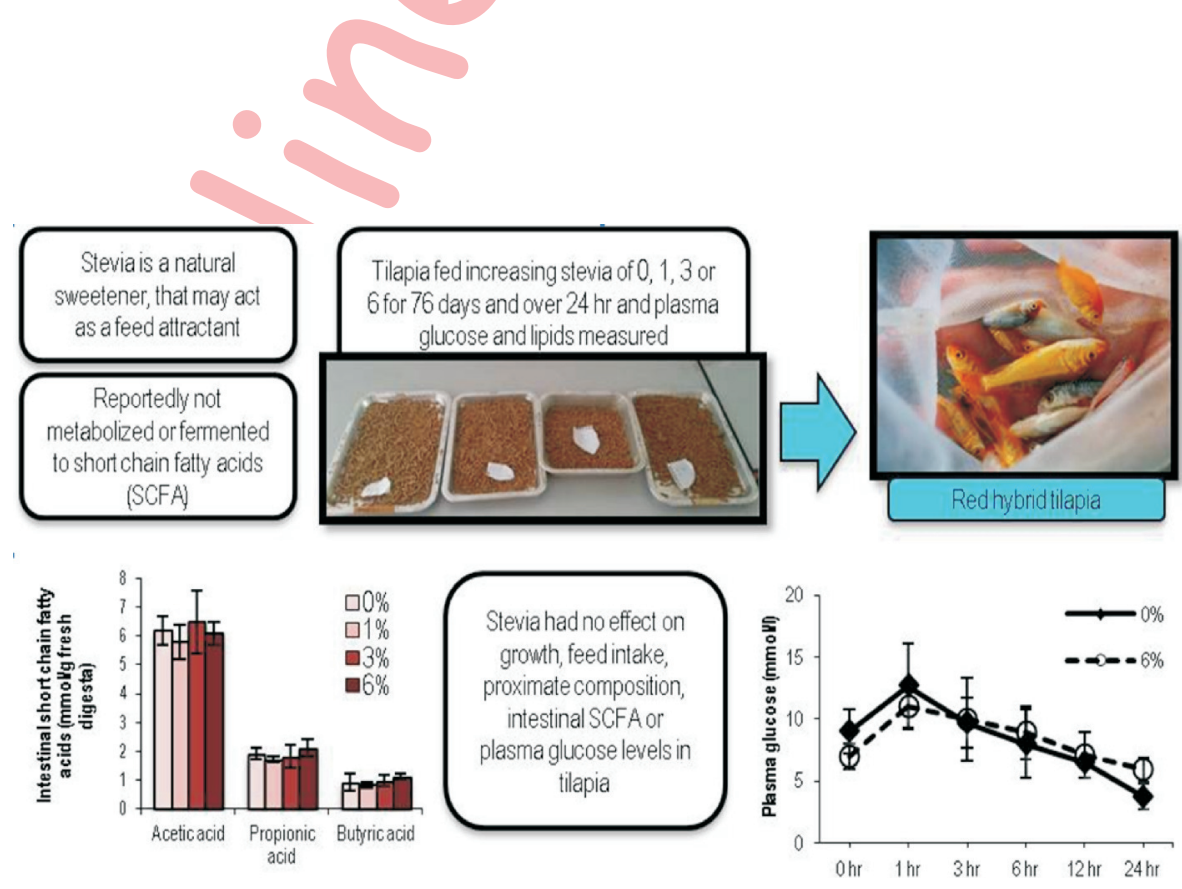




\section{Introduction}

Stevia (Stevia rebaudiana) is a natural herb containing active compound, steviol glycosides. Despite having a sweet taste, does not increase the glucose levels in various mammals, including humans (Goyal et al., 2010). Pure steviol glycosides have been recently approved by the Food and Drug Administration in 2017 for the food industry, and therefore interest in this plant as dietary supplements has increased. There are about 90 varieties of $S$. rebaudiana, currently being cultivated in the world (Ibrahim et al., 2008) and may be grown in nutrient poor soil, but the optimal temperature is $20-24^{\circ} \mathrm{C}$ (Singh and Rao, 2005). Some of the reported medicinal benefits of Stevia include having anti-hypergycemic, anti-hypertensive, anti-inflammatory and anti-oxidant properties (Melis, 2001; Chatsudthipong and Muanprasat, 2009; Yu etal., 2017).

There is limited information regarding dietary Stevia to fish (Shiozaki et al., 2004). In one study, Shiozaki et al. (2004) found that the addition of Stevia leaf extract at $0.2 \%$ had no effect on the growth, feeding efficiencies or body indices of rainbow trout, Oncorhynchus mykiss, after 4 weeks. However, when histamine was added to the diets of 0 . mykiss, Stevia extract protected against histamine-induced damage to their intestine, as well as mitigated a reduction to their a-tocopherol content in the liver (Shiozaki et al., 2004). The protective effect of Stevia leaf extract has also been observed in mammals (Takahashi et al., 2001; Shiozaki et al., 2006). Some of reasons for this included the anti-oxidant properties of Stevia, as well as blocking histamine intestinal absorption, preventing excessive peptic activity that would otherwise irritate the intestine, inhibiting $\mathrm{H}^{+} / \mathrm{K}^{+}$-ATPase activity, and therefore excessive $\mathrm{pH}$ changes and/or facilitate the degradation of histamine into less toxic components (Shiozaki et al., 2004).

Stevia is reportedly non-fermentable (Brandle et al., 1998), and in fact has been found to decrease short chain fatty acids (SCFA) in the cecum of broilers (Atteh et al., 2008). It was later demonstrated in vitro that Stevia can inhibit the growth of some probiotic bacteria capable of producing SCFA (Deninga et al., 2013). This would likely contribute to Stevia being nonfermentable in the intestine because SCFA are by-products of bacterial fermentation of certain compounds, such as prebiotics or other indigestible carbohydrates (Chen et al., 2017; Romano et al., 2018). Currently, there is no information on the effects of dietary Stevia to intestinal SCFA in fish, which are known to provide various benefits to the host animal, including acting as an energy source and antimicrobial to pathogenic bacteria (Hoseinifar et al., 2017).

The aim of this study was to determine the effects of increasing $(0,1,3$ and $6 \%)$ dietary Stevia (steviol glycosides) on the survival, growth, feed intake, muscle proximate composition and intestinal SCFAin red hybrid tilapia after 76 days.

\section{Materials and Methods}

Experimental diets : A total of 4 isonitrogenous and isolipidic diets were formulated with increasing amounts $(0,1,3$ and $6 \%)$ of Stevia (Steviol glycosides; SG95) that was obtained from PureCircle $^{\mathrm{TM}}$ (Jiangxi Province, China), at the expense of $\alpha$ cellulose. Stevia, ocoussed as a white powder, was kept at $-20^{\circ} \mathrm{C}$ and was used one year before the stated expiry date.

Danish fishmeal and soybean meal were the main protein sources, which were finely ground and sieved. All dry ingredients were thoroughly mixed for $30 \mathrm{~min}$ and then soybean oil and palm oil were added in equal amounts at the same time, which was mixed again. Distilled water was added at $20 \%$ of the dry ingredient weight and then this dough was mixed for another 15 min. This mash was then pelleted through a meat grinder according to Romano et al. (2018).

Diets were then oven-dried at $60^{\circ} \mathrm{C}$ for $5 \mathrm{hrs}$ and then broken into smaller pieces for the fish to consume it adequately. The pellets with 3 and $6 \%$ Stevia had a noticeable sweet smell. Feeds were then stored in plastic bags at $4^{\circ} \mathrm{C}$ until use within 2 weeks. Prior to starting this study, the proximate composition of the experimental diets was measured according to AOAC (1997).

Source of experimental animals, experimental design and analysis : Red hybrid tilapia (Oreochromis sp.) fingerlings (initial weight of $0.38 \pm 0.04$ ) were obtained from a local hatchery and brought to the Propagation Laboratory, Department of Aquaculture, Jerantut Community College, Pahang. After an initial two-day acclamation period in a 1,000 I fiberglass tank, 25 tilapia fingerlings were allocated into 12 fiberglass tanks (140 I) measuring $0.91 \times 0.61 \times 0.46 \mathrm{~m}$. All tanks were fitted with a recirculating system equipped with mechanical and biological filtration and the water flow was set at $21 \mathrm{I} \mathrm{min}^{-1}$. Each of the four treatments were triplicated and the fish were fed twice a day at 09:00 and 17:00 hr with their respective diets to apparent satiation.

The ammonia-N and nitrite-N levels were tested once per week prior to the water exchange from each aquarium using a commercial test kit (Aquarium Pharmaceuticals $®$ ). The mean $( \pm S D)$ ammonia- $N$ and nitrite-N was $0.25 \pm 0.01$ and $0.25 \pm 0.02$ $\mathrm{mg} / \mathrm{l}$, respectively, and both never exceeded $1.0 \mathrm{mg} \mathrm{l}^{-1}$. Once a week, the dissolved oxygen, $\mathrm{pH}$ and temperature were also measured using a digital probe (YSI Professional Plus Quatro) and these ranged from $5.4 \pm 0.5 \mathrm{ppm}, 7.8 \pm 0.3$, and $27 \pm 0.2^{\circ} \mathrm{C}$, respectively. The water source was sand and carbon filtered tap water and sodium thiosulphate was used to neutralize any residual chlorine.

After 76 days, all remaining fish were euthanized with clove oil and the fish were individually measured for their weights and lengths using a ruler $(0.1 \mathrm{~cm})$ and digital balance $(0.01 \mathrm{~g})$, respectively. This data was used to calculate the specific growth 
rate (SGR) for length and weight by the following equations:

SGR for weight $=$ specific growth rates $\left(\%\right.$ day $\left.^{-1}\right)=\left[\left(\operatorname{lnW}_{1}-\ln W_{0}\right) /\right.$ T] $\times 100$

where, $\mathrm{W}_{1}=$ final weight, $\mathrm{W}_{0}=$ initial weight and $\mathrm{T}=$ time in days

The feed conversion ratio (FCR) was also determined by the following equation:

FCR $=$ total dry weight of diet fed $(\mathrm{g}) /$ wet weight gain $(\mathrm{g})$

Body indices, proximate composition and intestinal short chain fatty acids : After measuring the weight and length, tilapia were then dissected to remove the viscera and liver to calculate the viscerosomatic index (VSI) and hepatosomatic index (HSI), respectively. The VSI and HSI were calculated by dividing the viscera and liver by the final body weight, respectively. The intestine (with digesta) was pooled from fish in the same tank for short chain fatty acid analysis according to Romano et al. (2016). From the remaining carcass, the heads, skin and fins were removed and the muscle was filleted, finely minced and pooled in each replicate. The muscle samples were then stored at $-20^{\circ} \mathrm{C}$ for further determination of the proximate composition.

Plasma glucose, triglycerides and cholesterol over time : Red hybrid tilapia (initial weight $80 \pm 2 \mathrm{~g}$ ) were obtained from a local hatchery in Serdang, Malaysia and transported to the Wet Laboratory, Department of Aquaculture, Faculty of Agriculture, UPM. The fish were acclimated in a 1,000 I fiberglass tank and fed the control diet for one days. Afterwards, tilapia were equally distributed among 6 glass tanks filled with 50 I water. Each tank had an individual mechanical and biological filter, as well as gentle aeration. The fish were further acclimated for one day and fed the control diet.

Table 1: Dietary ingredient and proximate composition (\% dry weight) of the experimental diets with increasing Stevia

\begin{tabular}{|c|c|c|c|c|}
\hline \multirow[t]{2}{*}{ Ingredients } & \multicolumn{3}{|c|}{ Experimental diets } & \multirow[b]{2}{*}{$6 \%$} \\
\hline & $0 \%$ & $1 \%$ & $3 \%$ & \\
\hline Fishmeal $^{a}$ & 12 & 12 & 12 & 12 \\
\hline Soybean meal $^{\mathrm{b}}$ & 48 & 48 & 48 & 48 \\
\hline Tapioca Starch $^{\circ}$ & 20.5 & 20.5 & 20.5 & 20.5 \\
\hline Soybean oil $^{c}$ & 4 & 4 & 4 & 4 \\
\hline Palm oil $^{c}$ & 4 & 4 & 4 & 4 \\
\hline Vitamin Premix $^{d}$ & 3 & 3 & 3 & 3 \\
\hline Mineral Premix ${ }^{d}$ & 2 & 2 & 2 & 2 \\
\hline Methionine $^{e}$ & 0.5 & 0.5 & 0.5 & 0.5 \\
\hline Stevia $^{\dagger}$ & 0 & 1 & 3 & 6 \\
\hline á-cellulose ${ }^{g}$ & 6 & 5 & 3 & 0 \\
\hline \multicolumn{5}{|c|}{ Proximate composition } \\
\hline Dry matter & 94.35 & 94.39 & 94.23 & 94.31 \\
\hline Crude protein & 32.58 & 32.39 & 32.45 & 31.72 \\
\hline Crude lipid & 9.17 & 9.24 & 9.01 & 9.43 \\
\hline Crude ash & 6.00 & 6.00 & 5.79 & 5.59 \\
\hline
\end{tabular}

Table 2 : Mean Specific growth rate (SGR) (\%/day) for weight, feed conversion ratio (FCR), total feed intake (FI) (g), hepatosomatic index (HSI), condition factor $(K)$ and survival $(\%)$ of red hybrid tilapia after 76 days of being fed diets with increasing levels of Stevia

\begin{tabular}{lllll}
\hline Parameters & \multicolumn{3}{c}{ Experimental diets } \\
\cline { 2 - 5 } & $\mathbf{0} \%$ & $1 \%$ & $3 \%$ & $6 \%$ \\
\hline SGR & $2.39 \pm 0.12$ & $2.32 \pm 0.04$ & $2.30 \pm 0.02$ & $2.31 \pm 0.02$ \\
FCR & $1.51 \pm 0.28$ & $1.65 \pm 0.13$ & $1.83 \pm 0.06$ & $1.72 \pm 0.07$ \\
FI & $94.04 \pm 0.55$ & $94.41 \pm 1.24$ & $101.66 \pm 0.43$ & $98.47 \pm 0.87$ \\
HSI & $1.12 \pm 0.23$ & $0.93 \pm 0.26$ & $0.94 \pm 0.12$ & $1.04 \pm 0.16$ \\
K & $2.19 \pm 0.12$ & $2.01 \pm 0.07$ & $1.92 \pm 0.03$ & $2.07 \pm 0.05$ \\
Survival (\%) & $81.67 \pm 4.40$ & $83.33 \pm 9.27$ & $91.67 \pm 1.67$ & $80.00 \pm 5.00$ \\
\hline
\end{tabular}

Values are mean $\pm S E$; No significant differences $(p>0.05)$ were detected among the treatments 


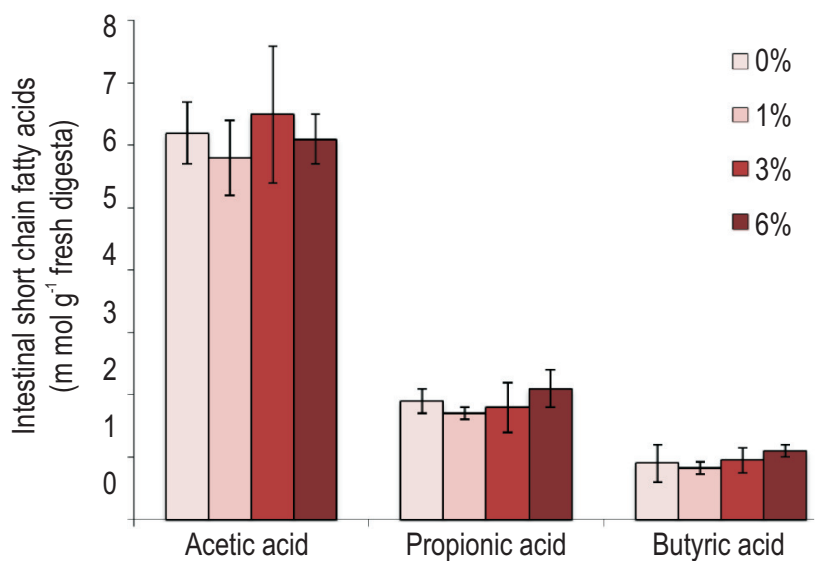

Fig. 1 : Intestinal short chain fatty acids ( $\mathrm{mmol} \mathrm{g}^{-1}$ fresh digesta) in tilapia fed increasing amounts of Stevia after 76 days. Values are mean $\pm S E$; No significant differences among treatments were detected $(p>0.05)$

The fish were fasted for $24 \mathrm{hr}$ and then 6 fish from each tank were removed, euthanized in clove oil and the blood was sampled by inserting a needle, which was attached to a syringe previously coated with a saturated EDTA solution, into their caudal vein. The blood was centrifuged at $603 \times \mathrm{g}$ for $10 \mathrm{~min}$ and then stored at $-20^{\circ} \mathrm{C}$. All remaining fish were then fed either with control diet ( $0 \%$ ) or $6 \%$ diet to apparent satiation at $0 \mathrm{hr}$. At 1, 3, 6, 12 and $24 \mathrm{hr}$ after feeding either diets, a total of 3 fish in each treatment were randomly selected and removed from the tank. Similalry as the fish sampled at $0 \mathrm{hr}$, the fish were anaesthetized, the blood was sampled, centrifuged and plasma stored at $-20^{\circ} \mathrm{C}$ for further analysis.

After all sampling (after $24 \mathrm{hr}$ ), the plasma was then analyzed for glucose, triglycerides and cholesterol within 2 days. Glucose levels were analyzed using BioLis 24i Premium Chemistry Analyzer, while levels of both cholesterol and triglycerides were measured on a SIEMENS Dimension ${ }^{\circledR}$ Xpand® Plus Instrument. During the acclimation time throughout the $24 \mathrm{hr}$ study, the mean dissolved oxygen, $\mathrm{pH}$ and temperature were $5.4 \pm 0.5 \mathrm{mgl}^{-1}, 7.8 \pm 0.3$ and $27 \pm 0.2^{\circ} \mathrm{C}$, respectively.

Data analysis : All data were tested for data homogeneity and normality before analysis by Levene's test and Shapiro-Wilks test, respectively. Data were subjected to One-way ANOVA and significant differences were considered if $p<0.05$.

\section{Results and Discussion}

There is increasing interest regarding the inclusion of natural ingredients, such as probiotics, prebiotics and various herbs and plants, in aquafeeds to potentially improve the growth, feed intake and/or overall health in fish and crustaceans (Reverter et al., 2014; Kareem et al., 2016). Despite Stevia being a highly potent sweetener, it had no effect on the feed intake in tilapia indicating that it did not improve diet palatability or appetite
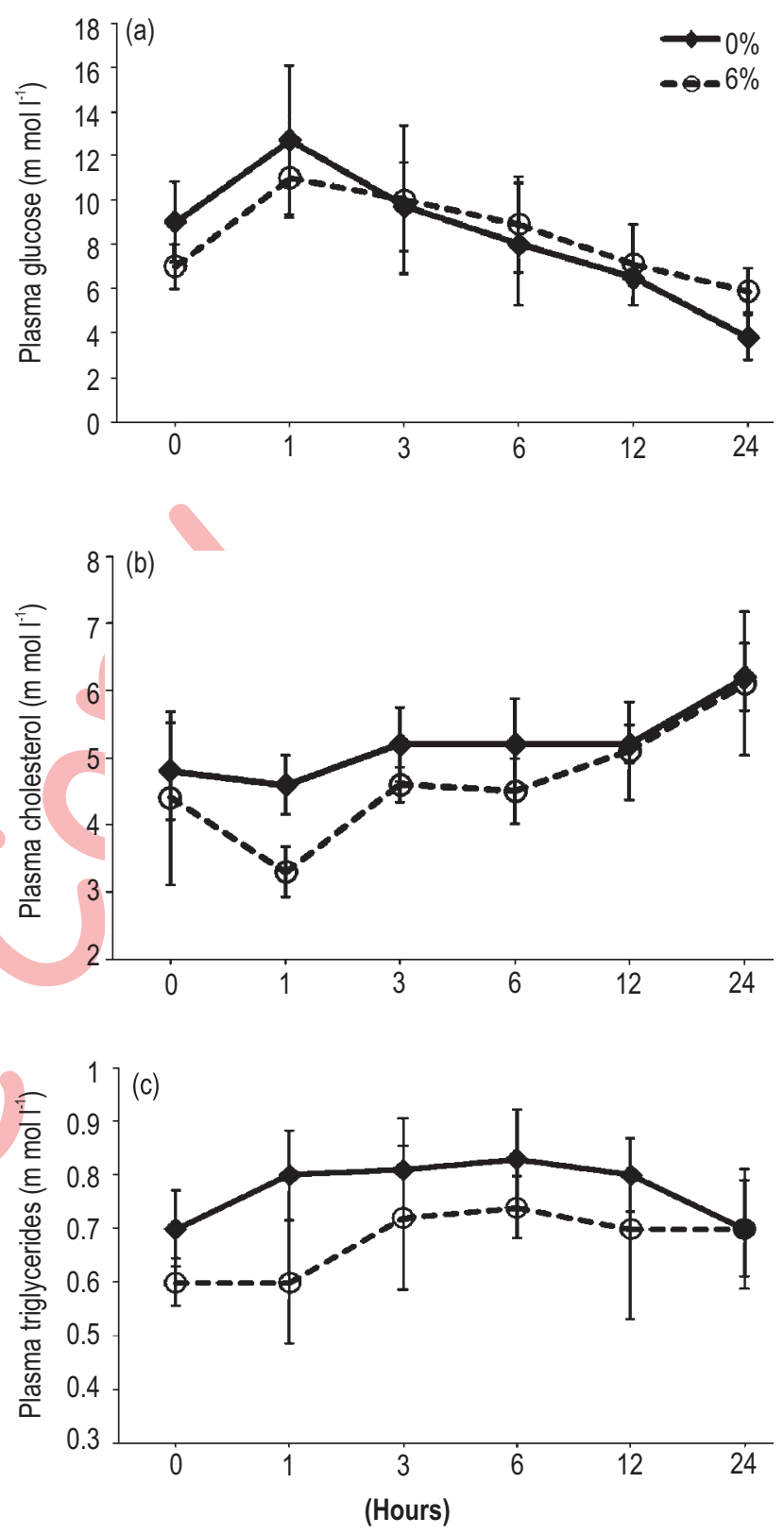

Fig. 2 : Plasma glucose (a), cholesterol (b) and triglycerides (c) at $0 \mathrm{hr}$ in red hybrid tilapia and after being fed 0 or $6 \%$ Stevia at 1, 3, 6, 12 and 24 hrs. Values are mean $\pm S E$; No significant differences were observed in these plasma parameters among treatments $(p>0.05)$

in tilapia. In contrast, 0 to $2 \%$ dried basil leaves improved the feed intake, as well as growth of Oreochromis niloticus $\times 0$. aureus fingerlings, possibly due to volatile oils that include ocimene, methyl chavecol and linalool (El-Daker et al., 2008).

In addition to Stevia having no effect on the feed intake of tilapia, the growth, feeding efficiencies, body indices and muscle proximate composition were also unaffected by dietary Stevia. This could be related to Stevia not being metabolized as an energy source in tilapia. This was later confirmed in the second 
Table 3 : Proximate composition (\% wet weight) of the muscles of red hybrid tilapia fed with increasing levels of Stevia after 76 days

\begin{tabular}{lllll}
\hline Parameters & \multicolumn{4}{c}{ Experimental diets } \\
\cline { 2 - 5 } & $\mathbf{0 \%}$ & $\mathbf{1 \%}$ & $\mathbf{3} \%$ & $\mathbf{6 \%}$ \\
\hline Moisture & $85.80 \pm 0.71$ & $83.19 \pm 1.29$ & $83.63 \pm 1.82$ & $83.89 \pm 1.42$ \\
Crude protein & $19.18 \pm 0.99$ & $18.16 \pm 1.59$ & $19.97 \pm 1.37$ & $17.96 \pm 0.52$ \\
Crude lipid & $4.42 \pm 0.34$ & $4.62 \pm 0.25$ & $4.31 \pm 0.79$ & $3.96 \pm 0.48$ \\
Crude ash & $1.11 \pm 0.50$ & $1.91 \pm 0.12$ & $1.82 \pm 0.22$ & $1.94 \pm 0.19$ \\
\hline
\end{tabular}

Values are mean \pm SE; No significant differences $(p>0.05)$ were detected among the treatments

experiment based on dietary Stevia having no effect on the plasma glucose, cholesterol or triglycerides compared to the control diet over $24 \mathrm{hr}$. It could be anticipated that if Stevia were being metabolized in the same way as simple sugars, there would be a temporary spike in plasma glucose (Tran-Duy et al., 2008). In mammals, plasma glucose was unaffected by Stevia intake, or in some cases, actually had a hypoglycemic effect (Chen et al., 2005; Anton et al., 2010). In contrast, $0.1 \%$ of inulin, which is a sweet tasting prebiotic, in the diets of tilapia was found to significantly increase the plasma glucose level, as well as growth (Tiengtam etal., 2015).

This study also showed that Stevia had no effect on intestinal SCFA after 76 days, which is consistent with reports that Stevia is non-fermentable (Brandle et al., 1998). It is known that SCFA can act as readily available energy to fish (Hoseinifar et al., 2017), and no change to these compounds by dietary Stevia could be another contributor for the absence of a growth improvement in tilapia. In contrast, prebiotics including maltooligosaccharides and fructooligosaccharides are known to be fermentable in the intestines of fish and crustaceans, respectively (Chen et al., 2017; Romano et al., 2018). In the case of fructooligosaccharides, a positive relationship between higher intestinal SCFA and growth was observed in the freshwater prawn Macrobrachium rosenbergii (Chen et al., 2017).

Some ingredients can be high in histamine, such as fishmeal, particularly if being over-processed by heat or starts getting spoilt (Masumura et al., 1984). Stevia is known to have some protective effects to histamine toxicity, as observed in fish (Shiozaki et al., 2004) and terrestrial animals (Takahashi et al., 2001; Shiozaki et al., 2006). However, tilapia appears to be less sensitive to histamine toxicity, possibly due to their low stomach pH (Reyes-Sosa and Castellanos-Molina, 1995). In conclusion, dietary Stevia at tested levels, in this study, showed no beneficial on the growth, feeding efficiencies, available energy or intestinal SCFA. This finding, along with a relatively low sensitivity of tilapia to histamine indicates that Stevia would provide no benefit in tilapia.

\section{Acknowledgments}

This study was partially funded by Southeast Asian Regional Center for Graduate Study and Research in Agriculture and from Universiti Putra Malaysia (UPM); project no. GPIPB/2014/9440403.

\section{References}

Anton, S.D., C.K. Martin, H. Han, S. Coulon, W.T. Cefalu, P. Geiselman and D.A. Williamson: Effects of stevia, aspartame and sucrose on food intake, satiety and postprandial glucose and insulin levels. Appetite, 55, 37-43 (2010).

Atteh, O.J., O.M. Onagbesan, K. Tona, E. Decuypere, J.M.C. Geuns and J. Buyse: Evaluation of supplementary stevia (Steiva rebaudiana, bertoni) leaves and stevioside in broiler diets: Effects on feed intake, nutrient metabolism, blood parameters and growth performance. Anim. Physiol. Anim. Nutr., 92, 640-649 (2008).

Brandle, J.E., A.N. Starratt and M. Gijzen: Stevia rebaudiana: Its agricultural, biological and chemical properties. Can. J. Plant Sci., 78, 527-536 (1998).

Chatsudthipong, V. and C. Muanprasat: Stevioside and related compounds: Therapeutic benefits beyond sweetness. Pharmacol. Therapeutics, 121, 1, 41-54 (2009).

Chen, T.H., S.C. Chen, P. Chan, Y.L. Chu, H.Y. Yang and J.T. Cheng: Mechanism of hypoglycemic effect of stevioside, a glycoside of Stevia rebaudiana. Planta Med., 71, 108-113 (2005).

Chen, W.W., N. Romano, M. Ebrahimi and I. Natrah: The effects of dietary fructooligosacchride on growth, intestinal short chain fatty acids level and hepatopancreatic condition of the giant freshwater prawn (Macrobrachium rosenbergii) post-larvae. Aquaculture, 469, 95-101 (2017).

Deninga I., P. Semjonovs, A. Fomina, R. Treimane and R. Linde: The influence of stevia glycosides on the growth of Lactobacillus reuteri strains. Lett. Appl. Microbiol., 58, 278-284 (2013).

El-Dakar, A., G.D. Hassanien, S.S Gad and S.E. Sakr: Use of dried basil leaves as a feeding attractant for hybrid tilapia, Oreochromis niloticus $\times 0$. aureus, fingerlings. Mediterranean Aquacult. J., 1, 35-44 (2008).

Goyal, S.K., Samsher and R.K. Goyal: Stevia (Stevia rebaudiana) a biosweetener: A review. Int. J. Food Sci. Nutri., 61, 1-10 (2010).

Hoseinifar, S.H., Y.Z. Sun and C.M. Caipang: Short-chain fatty acids as feed supplements for sustainable aquaculture: An updated review. Aquacult. Res., 48, 1380-1391 (2017).

Ibrahim, I.A., M.I. Nasr, B.R. Mohammedm and M.M. El-Zefzafi: Nutrient factors affecting in vitro cultivation of Stevia rebaudiana. Sugar Tech ., 10, 3, 248-253 (2008).

Kareem, Z.H., Y.M. Abdelhadi, A. Christianus, M. Karim and N. Romano: Effects of some dietary crude plant extracts on the growth and gonadal maturity of Nile tilapia (Oreochromis niloticus) and their 
resistance to Streptococcus agalactiae infection. Fish Physiol. Biochem., 42, 757-769 (2016).

Masumura, T., M. Sugawara, T. Noguchi, K. Mori and H. Naito: The effect of gizzerosine, a recently discovered compound in overheated fish meal, on the gastric acid secretion in chicken. Poult. Sci., 64, 356361 (1984).

Melis, M.S.: Inhibitory effect of stevioside on calcium influx to produce antihypertension. Planta Medica, 67, 796-799 (2001).

Reyes-Sosa, C.F. and R. Castellanos-Molina: Nutritional evaluation of gizzard erosion positive brown meal in starter diets for Nile tilapia, Oreochromis niloticus. Aquaculture, 138, 323-329 (1995).

Romano, N., S. Watson, M. Ebrahimi, A.H.I. Fadel, C.M. Chong and M.S. Kamarudin: Dietary sodium citrate improved oxidative stability in red hybrid tilapia (Oreochromis sp.) but reduced growth, health status, intestinal short chain fatty acids and induced liver damage. Aquaculture, 458, 170-176 (2016).

Romano, N., N. Kanmani, M. Ebrahimi, C.M. Chong, J.C. Teh, S.H. Hoseinifar, S.M.N. Amin, M.S. Kamarudin and V. Kumar: Combination of dietary pre-gelatinized starch and isomaltooligosaccharides improved pellet characteristics, subsequent feeding efficiencies and physiological status in African catfish, Clarias gariepinus, juveniles. Aquaculture, 484, 293-302 (2018).

Reverter, M., N. Bontemps, D. Lecchini, B. Banaigs and P. Sasal: Use of plant extracts in fish aquaculture as an alternative to chemotherapy: Current status and future perspectives. Aquaculture, 433, 50-61 (2014).
Shiozaki, K., T. Nakano, T. Yamaguchi, M. Sato and N. Sato: The protective effect of stevia extract on the gastric mucosa of rainbow trout Oncorhynchus mykiss (Walbaum) fed dietary histamine. Aquacult. Res., 35, 1421-1428 (2004).

Shiozaki, K., A. Fuiji, T. Yamaguchi and M. Sato: Inhibitory effects of hot water extract of the Stevia stem on the contractile response of the smooth muscle of the guinea pig ileum. Biosci. Biotechnol. Biochem., 70, 489-494 (2006).

Singh, S.D. and G.P. Rao: Stevia: The herbal sugar of $21^{\text {st }}$ century. Sugar Tech., 7, 17 (2005).

Takahashi, K., Y. Akiba, T. Nakano, T. Yamaguchi, M. Sato and N. Sato: Effect of dietary Stevia (Stevia rebaudiana) extract on gizzard erosion and ulceration induced by dietary histamine in broiler chicks. J. Poult. Sci., 38, 181-184 (2001).

Tiengtam, N., S. Khempaka, P. Paengkoum and S. Boonanuntanasam: Effects of inulin and Jerusalem artichoke (Helianthus tuberosus) as prebiotic ingredients in the diet of juvenile Nile tilapia (Oreochromis niloticus). Anim. Feed Sci. Technol., 207, 120-129 (2015).

Tran-Duy,A., B. Smit, A.A. van Dam and J.W. Schrama: Effects of dietary starch and energy levels on maximum feed intake, growth and metabolism of Nile tilapia, Oreochormis niloticus. Aquaculture, 277, 213-219 (2008).

Yu, H., G. Yang, M. Sato, T. Yamaguchi, T. Nakano and Y. Xi: Antioxidant activities of aqueous extract from Stevia rebaudiana stem waste to fish oil oxidation and identification of its phenolic compounds. Food Chem., 232, 379-386 (2017). 